\title{
First Trimester Combined Screening for Aneuploidy in South Indian Urban Population
}

\author{
Seshachalam Rathakrishnan Gayathri ${ }^{1}$, Lakshmi Shanmugasundaram ${ }^{2}$
}

\begin{abstract}
Aim:

- Evaluate the performance of first trimester combined screening (FTS) for Down's syndrome in singleton South Indian urban population.

- Use local data to counsel our women and their families.

Materials and methods: A retrospective study of singleton pregnancies who underwent the FTS from January 2013 to December 2015 . Nuchal translucency scan and double marker were offered to all pregnant women who booked before 13 weeks 5 days gestational age. Pre- and posttest counseling were provided by consultants in obstetrics. Screen positive for Down's syndrome was taken as a posttest risk cut-off of 1:250 and / or NT $>95$ th centile for gestation. The screen positives were offered a diagnostic test. Screen negatives were counseled about the low risk for Down's syndrome. The outcome of screening, diagnostic testing, and newborn phenotype and genotype were assessed.

Results: Among 735 singleton pregnancies screened, 2 Down's syndrome fetuses were identified on diagnostic testing (among 13 screen positives). The detection rate with screening was $100 \%$. There was a $1.5 \%$ false screen positive rate in singletons. There were no false-negatives during the study period.

Conclusion: The NHS United Kingdom screening program targets a detection rate of $90 \%$ for a screen positive rate of $2 \%$ using a posttest risk cut-off 1 in 150 or NT > 95th centile. First trimester Down's syndrome screening in this study of urban South Asian population had a 1.5\% falsepositive rate and $0 \%$ false-negative rate. The study analysis was based on a posttest risk cut-off of 1 in 250 . All true screen positives had a risk cut-off of 1 in 150.

Clinical significance: A risk cut-off of 1 in 150 appears to apply to our population when FTS is performed following the standards set by the fetal medicine foundation.

Keywords: Combined screening, Down's syndrome, Retrospective study, Singleton.

Journal of South Asian Federation of Obstetrics and Gynaecology (2020): 10.5005/jp-journals-10006-1850
\end{abstract}

\section{INTRODUCTION}

Down's syndrome occurs in 1 out of every 700 babies $^{1}$ in all racial groups.

The first trimester combined test with a detection rate of $85-90 \%{ }^{2}$ is the current best cost-effective prenatal aneuploidy screening. Second-trimester serum markers have a less detection rate and despite the best detection rates with noninvasive fetal karyotyping it is expensive hence not suitable for general population screening.

Outcomes from pregnancy screening require periodic evaluation to ensure the expected standards are achieved. An audit is a useful tool in such evaluations. Our study aims to evaluate first trimester combined screening (FTS) in singleton South Indian urban population with FASP audit standards 2018 issued for the National health service. Both health care systems are very different, private health care system in India compared to universal free availability in the UK. But Down's syndrome prevalence has no racial variation. Median values for FTS markers - serum PAPPA, free beta hCG — are determined from the local population, and MoMs are calculated. With the use of FMF licensed FTS PRISCA software, reliable lab parameters and posttest risk calculation can be obtained. With the use of standardized software incorporating relevant correction factors for the parameters that affect PAPPA and hCG-race, IVF conception, past history of Down's, insulin for diabetes there is universal reliability in FTS results. First trimester combined screening is a population-based screening test hence using the
${ }^{1}$ Department of Obstetrics and Gynaecology, ESIC Medical College and Postgraduate Institute of Medical Sciences and Research, Chennai, Tamil Nadu, India

${ }^{2}$ Institute of Reproductive Medicine, Madras Medical Mission, Chennai, Tamil Nadu, India

Corresponding Author: Seshachalam Rathakrishnan Gayathri, Department of Obstetrics and Gynaecology, ESIC Medical College and Postgraduate Institute of Medical Sciences and Research, Chennai, Tamil Nadu, India, Phone: +919444037128, e-mail: dr.sr.gayathri@ gmail.com

How to cite this article: Gayathri SR, Shanmugasundaram L. First Trimester Combined Screening for Aneuploidy in South Indian Urban Population. J South Asian Feder Obst Gynae 2020;12(5):281-283.

Source of support: Nil

Conflict of interest: None

well-established screening guidelines in the UK was considered as the most relevant audit standard. The posttest risk of 1 in 250 was the screen positive cut-off in our population. This was the initial cut-off used by NHS. During 2010, there were changes made to the Down's syndrome screening. First trimester combined test, the gestational age range for nuchal translucency is from $11^{+2}$ to $14^{+1}$ weeks (previously up to $13^{+6}$ weeks), and nuchal translucency should be when the crown-rump length is between 45 and 84 $\mathrm{mm}$ (previously up to $80 \mathrm{~mm}$ ). There was also the enactment of quadruple testing for patients who present after 14 weeks instead 
of the triple test. The cut-off for high risk of screening tests changed from 1:250 to $1: 150 .^{3}$

Apart from ensuring standards for FTS were met, identification of areas for improvement, the outcome from this audit will be useful to provide local data that can be utilized in FTS counseling.

\section{Materials and Methods}

A retrospective study of the FTS program in singleton pregnancies is to detect Down's syndrome. The study population consisted of all women who underwent FTS between January 2013 and December 2015 and completed their antenatal care, delivery at the Institute of Reproductive Medicine (IRM).

The antenatal care pathway for women undergoing first trimester screening consisted of the following:

- Scan at 11 to $13^{+6}$ weeks when fetal CRL is between 45 and $84 \mathrm{~mm}$ for nuchal translucency and nasal bone performed in keeping with the FMF standards.

- Pre- and posttest counseling were done by the respective obstetricians following a standard template and information leaflets given to all antenatal women.

- All blood samples were collected on the same day as the NT scan and sent for double marker analysis to a single outsourced lab using PRISCA software.All relevant details (date of birth, race, weight, height, gestational age, present and past pregnancy complications, CRL, NT, and nasal bone) were included in the test request and incorporated in result analysis.

- Results were reviewed and checked for accuracy of contents by a consultant obstetrician.

- Screen positive for Down's syndrome was a posttest risk cut-off of 1:250 and/or NT >95th centile for gestation and these women were counseled for the diagnostic test-amniocentesis/CVS.

\section{Inclusion Criteria}

Antenatal women who attended for first trimester NT scan $\left(11-13^{+6}\right.$ weeks) and combined test between January 2013 and December 2015 and delivered at our unit.

\section{Exclusion Criteria}

Late booking $>14$ weeks, suboptimal position for NT image, the couple declined double test, moved out of IRM for delivery.

\section{Results}

The total number of pregnant singleton included in the study was 735. In the study group of 735 singletons, 2 fetuses had confirmed Down's syndrome.

There were no other aneuploidies detected during the study period.

No. of antenatal women with a priori high risk was 93 (12.6\%) of which 1 had past Down's and 92 women were advanced maternal age $>35$ years.

Thirteen were screen positive (1.7\%) of which 1 patient opted for NIPT and the rest 12 screen positive opted for diagnostic testing.

Of the 12 patients who opted for amniocentesis, 10 had normal karyotyping and 2 were positive for Down's.

$1.5 \%$ false-positive rate, $0 \%$ false-negative rate in the audit period.

Characteristics of antenatal women who underwent first trimester screening are given in Tables 1 to 5 .

\section{Discussion}

- The detection rate in our study was $100 \%$ with a $1.5 \%$ falsepositive rate which was comparable with the audit standards set. The NHS United Kingdom screening program 2010 check is population-based targeting at a detection rate of $90 \%$ for a screen positive rate of $2 \%$ using a posttest risk cut-off 1 in 150 or NT >95th centile. ${ }^{4}$ Cochrane review 2015 states that FTS detects around 7 out of every $10(68 \%)$ pregnancies affected by Down's. About 1 in 20 women (5\%) having this test will have a "high risk" result but most of these women will not be carrying a baby with $\mathrm{T} 21 .^{5}$

Table 1: Age distribution of women

\begin{tabular}{lcl}
\hline Age group & No. of women & Percentage \\
\hline 16-24 years & 75 & 10.2 \\
$25-29$ years & 318 & 43.27 \\
$30-34$ years & 250 & 34.01 \\
$35-39$ years & 79 & 10.75 \\
$>40$ years & 13 & 1.77 \\
\hline
\end{tabular}

Table 2: Gestational age at screening

\begin{tabular}{lcc}
\hline $\begin{array}{l}\text { Gestational age at } \\
\text { screening }\end{array}$ & No. of women & Percentage \\
\hline $77-83$ days & 44 & 5.98 \\
$84-90$ days & 448 & 60.95 \\
$91-97$ days & 243 & 33.06 \\
\hline
\end{tabular}

Table 3: Screen positives

\begin{tabular}{lll}
\hline & True positive & False positive \\
\hline $\begin{array}{l}\text { No. of screen-positive } \\
\text { women }\end{array}$ & 2 & 11 \\
Amniocentesis & 2 & 10 \\
NIPT & - & 1 \\
$\begin{array}{l}\text { Post-procedure } \\
\text { miscarriage }\end{array}$ & 1 & - \\
\hline
\end{tabular}

Table 4: Performance of the first trimester combined screening

\begin{tabular}{lc}
\hline Parameter (\%) & Singletons \\
\hline Sensitivity & 100 \\
Specificity & 98.5 \\
False-positive rate & 1.5 \\
Positive predictive value & 15.38 \\
Negative predictive value & 100 \\
Diagnostic accuracy & 100 \\
\hline
\end{tabular}

Table 5: Screening results for fetuses with Down's syndrome

\begin{tabular}{lllll}
\hline $\begin{array}{l}\text { Maternal } \\
\text { age years }\end{array}$ & $\begin{array}{l}\text { PAPPA } \\
\text { (MoM) }\end{array}$ & $\begin{array}{l}\text { Free beta } \\
\text { hCG }(\text { MoM) }\end{array}$ & NT (MoM) & $\begin{array}{l}\text { Risk of } \\
\text { trisomy 21 }\end{array}$ \\
\hline $\begin{array}{l}33 \text { (True } \\
+ \text { ve) }\end{array}$ & 0.84 & 2.01 & 1.87 & $1: 53$ \\
$\begin{array}{l}34 \text { (True } \\
\text { +ve) }\end{array}$ & 0.11 & 1.03 & 1.07 & $1: 139$ \\
\hline
\end{tabular}


- There is a need for offering aneuploidy screening before 18 weeks given the medical and social dynamics that these conditions entail.

- Special care with the counseling pre- and posttest is required to ensure there is an understanding of why the test is being performed. For low-risk screening posttest, counseling should make it clear that there is a low probability of an affected child with trisomy rather than a no possibility.

- Also, antenatal detailed review of anatomy in the second trimester is vital as the risk of having Down's affected baby increases three to four times when the following are detected: thickened nuchal fold, mild fetal pyelectasis, echogenic bowel, echogenic intracardiac focus, choroid plexus cyst, ventriculomegaly, aberrant subclavian artery, and short limbs. The risk increases six or seven times when there is an absent or small nasal bone.

- First trimester aneuploidy scan and the combined test is the current most cost-efficient screening and hence all units should periodically evaluate their test performance. The limitation in our study was the small sample size for the audit.

\section{Conclusion}

Our population detection rate, false-positive rate, and true-positive rates among singletons met the expected standard.
- A good screening test is characterized by a high detection rate, a low screen positive rate.

- Apart from the two fetuses confirmed by antenatal testing two Down's babies were born in our unit during this study period but neither had any aneuploidy screening done and were seen in our center from the third trimester only-this reiterates offering aneuploidy screening and auditing its performance is vital. Our standards need to be maintained and re-audited periodically and a risk cut-off of 1 in 150 applies to our population.

\section{References}

1. Parker SE, Mai CT, Canfield MA, et al. Updated national birth prevalence estimates for selected birth defects in the United States, 2004-2006. Birth Defects Res A Clin Mol Teratol 2010;88(12):10081016. DOI: 10.1002/bdra.20735.

2. UK National Screening Committee Key performance indicators for screening 2011-2012.

3. Zehrer T, Stankeviciene I, Abdel-Aal M, Comparison of National Downs screening uptake, results, and outcomes to a district general hospital, 2014 - fetalmedicine.org.

4. McEwan A, Godfrey A, Wilkins J. Screening for down syndrome. Obstetr, Gynaecol Reproduct Med 2012;22(3):70-75. DOI: 10.1016/j. ogrm.2012.01.006.

5. Alldred SK, Takwoingi Y, Guo B, et al. First trimester serum tests for down's syndrome screening. Cochrane Database Syst Rev 2015(11):CD011975. DOI: 10.1002/14651858.CD011975. 